Document downloaded from:

http://hdl.handle.net/10251/122554

This paper must be cited as:

Bouhjar, F.; Mollar García, MA.; Chourou, M.; Marí, B.; Bessais, B. (2018). Hydrothermal synthesis of nanostructured $\mathrm{Cr}$-doped hematite with enhanced photoelectrochemical activity. Electrochimica Acta. 260:838-846. https://doi.org/10.1016/j.electacta.2017.12.049

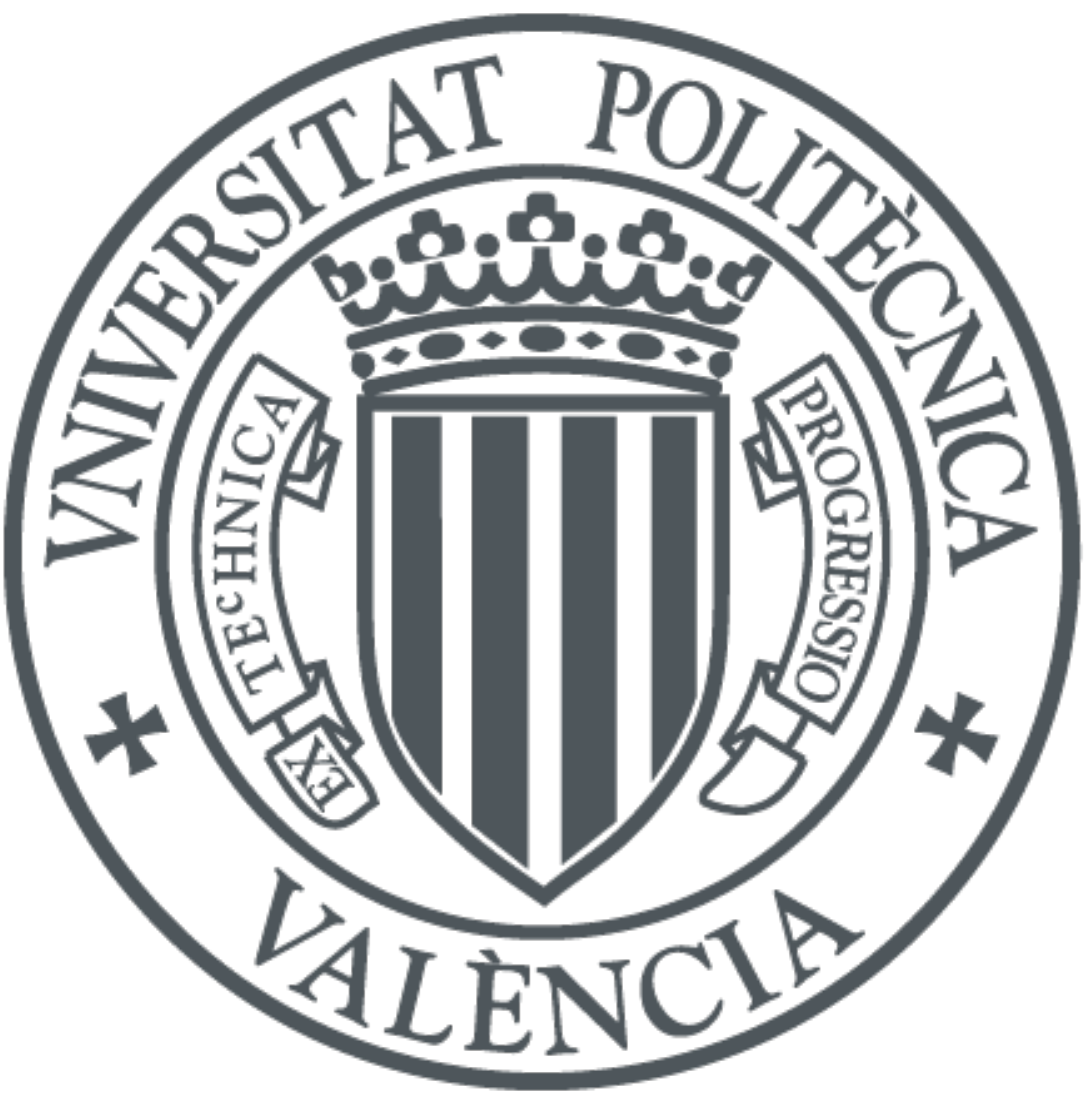

The final publication is available at

https://doi.org/10.1016/j.electacta.2017.12.049

Copyright Elsevier

Additional Information 


\title{
Hydrothermal synthesis of Nanostructured Cr-doped hematite with enhanced photoelectrochemical activity
}

\author{
F. Bouhjar ${ }^{a, b, c}$, M. Mollar ${ }^{a}$, M.L. Chourou ${ }^{b}$, B. María and B. Bessaïs ${ }^{b}$ \\ a. Institut de Disseny i Fabricació (IDF) - Departament de Física Aplicada, Universitat \\ Politècnica de València, Camí de Vera s/n, 46022 València, Spain. \\ b. Photovoltaic Laboratory, Research and Technology Centre of Energy, Borj-Cedria \\ Science and Technology Park, BP 95, 2050 Hammam-Lif, Tunisia \\ c. University of Tunis
}

\begin{abstract}
Using the easily applicable hydrothermal method Cr-doped hematite thin films have been deposited polycrystalline on conductive glass substrates. The hydrothermal bath consisted of an aqueous solution containing a mixture of $\mathrm{FeCl}_{3} .6 \mathrm{H}_{2} \mathrm{O}$ and $\mathrm{NaNO}_{3}$ at $\mathrm{pH}=1.5$. The samples were introduced in an autoclave and heated for a fixed time at a fixed temperature and then annealed in air at $550^{\circ} \mathrm{C}$. The concentration of the incorporated $\mathrm{Cr}$ atoms $\left(\mathrm{Cr}^{4+}\right.$ ions $)$ was controlled by varying the concentration of the $\mathrm{Cr}\left(\mathrm{ClO}_{4}\right)_{3}$ precursor solution, varied from $0 \%$ to $20 \%$. All samples followed morphological and structural studies using field-emission scanning electron microscopy, high-resolution transmission electron microscopy and X-ray diffraction. Chronoamperometry measurements showed that $\mathrm{Cr}$-doped hematite films exhibited higher photoelectrochemical activity than the undoped films. The maximum photocurrent density and incident photon conversion efficiencies (IPCE) were obtained for 16 at.\% Cr-doped films. This high photoactivity can be attributed to both the large active surface area and increased donor density caused by $\mathrm{Cr}$-doping in the $\boldsymbol{\alpha}-\mathrm{Fe}_{2} \mathrm{O}_{3}$ films. All samples reached their best IPCE at 400 nm. IPCE values for 16 at.\% Cr-doped hematite films were thirty times higher than that of undoped samples. This high photoelectrochemical performance of Cr-doped hematite films is mainly attributed to an improvement in charge carrier properties.
\end{abstract}

Keywords: Thin films; Hematite; Chromium; XRD analysis; FESEM analysis; TEM analysis; Optical properties; Photoelectrochemical properties. 


\section{Introduction}

For the last twenty years, hematite $\left(\alpha-\mathrm{Fe}_{2} \mathrm{O}_{3}\right)$ is considered as the most promising material in view of cost, abundance and photocatalytic properties. Hematite has emerged as an efficient photocatalyst used in solar water splitting as well as hydrogen production due to its appropriate optical band gap (2.1-2.2 eV). According to theoretical predictions, solar-to-hydrogen efficiency of hematite can reach $16.8 \%$ and water splitting photocurrent can extent 12.6 $\mathrm{mA} / \mathrm{cm}^{2}[1,2,3]$. Moreover, hematite exhibits an extraordinary chemical stability in an oxidative environment. However, the applied performance of hematite for solar water splitting is far from the ideal case which has been limited by several factors such as poor conductivity, short lifetime of the excited state carrier (10 ps), poor oxygen evolution reaction (OER) kinetics, short hole diffusion length, and improper band position for an unbiased Photoelectrochemical method [4]. So far, the photoelectrochemical activity (PECA) of hematite has remained quite low because of two main drawbacks. First, the conduction band edge energy of $\boldsymbol{\alpha}-\mathrm{Fe}_{2} \mathrm{O}_{3}$ system lies below the reversible hydrogen potential, thus hindering the charge-transfer process of photogenerated carriers (electrons and holes) at the hematite/electrolyte. Second, undoped hematite exhibits a rapid non-radiative electron-hole recombination due to its high density of intrinsic defects. As a result, the defects induce a short diffusion length almost $4 \mathrm{~nm}$ compared to the light penetration depth. Therefore, hematite has a relatively poor conductivity, severely limiting the overall photocurrent. However, incorporating foreign metallic atoms into the $\alpha-\mathrm{Fe}_{2} \mathrm{O}_{3}$ structure has been considered an effective approach to inhibit the above-mentioned drawbacks and consequently enhance the PECA of hematite.

A large range of elements, mostly belonging to transition metals such as $\mathrm{Sn} \mathrm{[5],} \mathrm{Cu}$ [6], $\mathrm{Pt} \mathrm{[7],}$ Si [8,9,10,11], Ti [12,13,14], V [7], Al [7,15], Cd [16], Mo [17], Nb [18], Mg [7], Rh [19], Ce [20], $\mathrm{Co}$ [21], $\mathrm{Cu}$ [7,22], $\mathrm{Zn}$ [7,23], Cr [7,17], Pt[11], and Ta [24] have been used to dope hematite. Table I shows a review of the achievements in some typically doped $\boldsymbol{\alpha}-\mathrm{Fe}_{2} \mathrm{O}_{3}$ that can be found in the literature. Data in Table I includes the kind of the doping agents and the performance of the hematite water splitting photoelectrodes. These data are compared with the Cr-doped hematite obtained from the hydrothermal method described in this work. To dope $\boldsymbol{\alpha}-$ $\mathrm{Fe}_{2} \mathrm{O}_{3}$, diverse methods have been attempted, using a range of synthesizing methods including sol-gel [25,26,27], hydrothermal [28,29], magnetron sputtering [30,31], atomic layer deposition [32], spray pyrolysis [8,33,34,35], atmospheric pressure chemical vapor deposition (APCVD) [11,36,37], and electrodeposition [38,39,40,41]. These dopants influence the conductivity of the hematite as well as band gap width, the Fermi level, and charge-transfer- 
processes. However, based on the literature, some researchers reported contradictory effects of doping on photoelectrochemical performances. This apparent discrepancy in the results has mainly been attributed to the doping concentration and processing methods. Undoped and doped hematites have been grown by various methods that can roughly be categorized in two groups. The first group involves physical deposition using gas as precursors and necessitates expensive and sophisticated devices as is the case in atomic layer deposition, chemical vapor deposition and magnetron sputtering. The second group includes wet chemical synthesizing methods requiring solution precursors and relatively low cost, simple utensils or set ups as in the case of electrochemical deposition, spray pyrolysis, sol-gel coating and hydrothermal growth. Compared to the methods, the hydrothermal method has several advantages. First, it is a reproducible, facile and inexpensive method since it consists of sealed "one pot" reactions requiring an operating temperature as low as $100{ }^{\circ} \mathrm{C}$. Second, it allows crystalline growth of versatile nanostructured doped hematite with precise control of the microstructure morphologies. Recently, McFarland and co-workers [38] were able to fabricate Pt, Mo and Cr doped and undoped hematite films as PEC electrodes for water splitting. They found that the photoactivity of the iron oxide was improved by co-deposition with Mo or Cr. The best performing samples were 5\% $\mathrm{Cr}$ and 15\% Mo doped, which had IPCEs at $400 \mathrm{~nm}$ of $6 \%$ and $12 \%$, respectively, with an applied potential of $0.4 \mathrm{~V}$ vs $\mathrm{Ag} / \mathrm{AgCl}$. These IPCE values were 2.2 and 4 times higher than the undoped sample for the $5 \% \mathrm{Cr}$ and $15 \%$ Mo samples, respectively. No evidence was found that the improved performance was due to the electrocatalytic effects of the dopant at the surface of the hematite thin film. The major effect of the Mo and Cr dopants is to improve the charge transport properties of the hematite so that a greater fraction of the photon generated electron/hole pairs is available for surface redox chemistry.

Furthermore, under factual operating conditions, high overpotentials are desirable not only because of non-idealities but also due to the complexity of water splitting reactions. Current progress in nanostructured hematite synthesis including nanoparticles [42,43], nanowires [44] and nanonets [45] opens opportunities in tackling the drawbacks mentioned above. As a matter of fact, nanostructured photoanode offers an increased semiconductor/electrolyte interfacial area for water oxidation, as well as a substantial reduction of the diffusion length for minority carriers $[46,47,48]$.

In this way, hole recombination can be decreased if the surface feature dimensions are tuned to be close to the hole diffusion length of $\boldsymbol{\alpha}-\mathrm{Fe}_{2} \mathrm{O}_{3}(2-4 \mathrm{~nm}$ [49] or $20 \mathrm{~nm}$ [50]). Nanostructures increase light absorption by increasing light scattering and trapping. As a result, nanostructured 
hematite photoelectrodes greatly facilitate the collection of charge carriers better than if they were simply bulky and smooth [51]. An additional doping of hematite photoanodes has been extensively studied to perform a further enhancement of the photoactivity of these photoanodes $[51,52,53]$. Numerous studies have shown that PEC water splitting is advantageous combining nanostructure and doping effects [54,55].

Therefore, a more straightforward and up scaling fabrication method of nanostructured doped hematite electrodes is needed to compare the doping effects in terms of PECA before addressing their stability under real operating conditions.

To date, no significant data have been published on optical, structural and electrical properties as well as PECA of chrome doped $\boldsymbol{\alpha}-\mathrm{Fe}_{2} \mathrm{O}_{3}$ films when synthesized by the hydrothermal method. In this study, we prepared $\mathrm{Cr}$-doped $\boldsymbol{\alpha}-\mathrm{Fe}_{2} \mathrm{O}_{3}$ thin films by a hydrothermal process. The photoelectrochemical response shows that the samples are effective for the photo splitting of water and the doping level affects the photocatalytic of the thin films. The optimum sample is $\boldsymbol{\alpha}-\mathrm{Fe}_{2} \mathrm{O}_{3}$ doped with 16 at.\% Cr. It is believed that this result could be beneficial for the applications of $\mathrm{Cr}$-doped $\boldsymbol{\alpha}-\mathrm{Fe}_{2} \mathrm{O}_{3}$ in the fields of photocatalysis and photoelectrical devices.

Table I: Summary of the results obtained for doped hematite photoelectrodes, fabrication methods and photoelectrochemical characteristics

\begin{tabular}{|c|c|c|c|c|c|c|c|}
\hline Dopant & $\begin{array}{c}\text { Preparation } \\
\text { Method }\end{array}$ & $\begin{array}{c}\text { Potential } \\
\text { (V) }\end{array}$ & Electrolyte & $\begin{array}{c}\text { Light } \\
\text { Intensity } \\
\left(\mathbf{m W} \cdot \mathbf{c m}^{-2}\right)\end{array}$ & $\begin{array}{c}\text { IPCE } \\
(\%)\end{array}$ & $\begin{array}{c}\text { Photocurrent } \\
\text { Density } \\
\left(\mathbf{m A} \cdot \mathbf{c m}^{-2)}\right.\end{array}$ & Ref. \\
\hline $\begin{array}{l}\text { undoped } \\
\text { Mo } \\
\mathrm{Cr}\end{array}$ & Electrodeposition & $\begin{array}{c}0.4 \text { vs. } \\
\mathrm{Ag} / \mathrm{AgCl}\end{array}$ & $1 \mathrm{M} \mathrm{NaOH}$ & 410 & $\begin{array}{c}3 \\
12 \\
6\end{array}$ & $\begin{array}{c}0.690 \\
2,00 \\
1,2\end{array}$ & [17] \\
\hline $\begin{array}{c}\text { Undoped } \\
\mathrm{Si} \\
\mathrm{Ti}\end{array}$ & Sputtering & $\begin{array}{l}0.5 \text { vs. } \\
\text { SCE }\end{array}$ & $1 \mathrm{M} \mathrm{NaOH}$ & 100 & $\begin{array}{c}\text { U.A. } \\
3 \\
15\end{array}$ & $\begin{array}{c}\text { Negligible } \\
0.100 \\
0.620\end{array}$ & [53] \\
\hline $\begin{array}{c}\text { Undoped } \\
\text { Ti } \\
\text { Ti-Al } \\
\text { Ta } \\
\text { Ti-Pt } \\
\text { Ni } \\
\end{array}$ & Spray Pyrolysis & $\begin{array}{l}0.45 \text { vs. } \\
\text { NHE }\end{array}$ & $0.1 \mathrm{M} \mathrm{NaOH}$ & U.A. & U.A. & $\begin{array}{c}0.800 \\
4.000 \\
4.000 \\
1.000 \\
0.800 \\
\text { Negligible } \\
\end{array}$ & [52] \\
\hline $\begin{array}{l}\text { Undoped } \\
\mathrm{Pt}\end{array}$ & Electrodeposition & $\begin{array}{c}0.4 \mathrm{vs} . \\
\mathrm{Ag} / \mathrm{AgCl}\end{array}$ & $1 \mathrm{M} \mathrm{NaOH}$ & 410 & $\begin{array}{c}3 \\
12\end{array}$ & $\begin{array}{l}0.690 \\
1.340\end{array}$ & [38] \\
\hline $\begin{array}{c}\text { Undoped } \\
\mathrm{Al}\end{array}$ & Electrodeposition & $\begin{array}{c}0.4 \text { vs. } \\
\mathrm{Ag} / \mathrm{AgCl}\end{array}$ & $1 \mathrm{M} \mathrm{NaOH}$ & 410 & $\begin{array}{l}3 \\
8\end{array}$ & $\begin{array}{c}0.690 \\
\sim 1.000\end{array}$ & [39] \\
\hline $\begin{array}{c}\text { Undoped } \\
\mathrm{Ti}\end{array}$ & Spray Pyrolysis & $\begin{array}{c}0.5 \text { vs. } \\
\text { SCE }\end{array}$ & $1 \mathrm{M} \mathrm{NaOH}$ & 150 & U.A. & $\begin{array}{c}\text { Negligible } \\
1.980\end{array}$ & [56] \\
\hline $\begin{array}{c}\text { Undoped } \\
\mathrm{Mg}\end{array}$ & Spray Pyrolysis & $\begin{array}{c}0.2 \text { vs. } \\
\text { SCE }\end{array}$ & $0.5 \mathrm{M} \mathrm{H}_{2} \mathrm{SO}_{4}$ & U.A. & U.A. & $\begin{array}{l}\text { U.A. } \\
0.22\end{array}$ & [57] \\
\hline
\end{tabular}




\begin{tabular}{|c|c|c|c|c|c|c|c|}
\hline $\begin{array}{c}\text { Undoped } \\
\mathrm{Zn}\end{array}$ & Spray Pyrolysis & 0 vs. SCE & $0.5 \mathrm{M} \mathrm{H}_{2} \mathrm{SO}_{4}$ & 40 & $\begin{array}{c}\text { U.A. } \\
20\end{array}$ & $\begin{array}{c}\text { U.A. } \\
\text { U.A. }\end{array}$ & {$[58]$} \\
\hline $\begin{array}{c}\text { Undoped } \\
\mathrm{Cr}\end{array}$ & Hydrothermal & $\begin{array}{c}0.1 \mathrm{vs.} \\
\mathrm{Ag} / \mathrm{AgCl}\end{array}$ & $1 \mathrm{M} \mathrm{NaOH}$ & \multirow{2}{*}{100} & $\begin{array}{c}\text { Negligible } \\
6\end{array}$ & $\begin{array}{c}1.77 \\
2.68\end{array}$ & $\begin{array}{c}\text { our } \\
\text { work }\end{array}$ \\
\hline
\end{tabular}

U.A. = Unavailable

\section{Experimental}

\subsection{Material and methods}

The flowchart illustrating the synthesis of nanostructured $\boldsymbol{\alpha}-\mathrm{Fe}_{2} \mathrm{O}_{3}$ thin films by the hydrothermal method is displayed in Figure 1. Initially, a fluorine-doped tin oxide (FTO) coated glass plate purchased from Pilkington glass company (USA), was cut into small rectangular pieces having a surface of $3 \times 1 \mathrm{~cm}^{2}$ to serve as a starting substrate. These pieces were ultrasonically pre-cleaned by sequential rinses with acetone, distilled water, and ethanol. The hydrothermal bath was an aqueous solution containing a solution $0.15 \mathrm{M} \mathrm{FeCl}_{3}, 1 \mathrm{M} \mathrm{NaNO}$ and $1 \mathrm{M} \mathrm{Cr}\left(\mathrm{ClO}_{4}\right)_{3}[59,60,61]$. Some drops of hydrochloric acid $(\mathrm{HCl})$ were added to adjust the $\mathrm{pH}$ of the mixture to 1.5. $\mathrm{Cr}\left(\mathrm{ClO}_{4}\right)_{3}$ solutions were added to the bath intended for $\mathrm{Cr}$-doped films. The additional amount of $\mathrm{Cr}$ was calculated so that the molar ratio $\mathrm{Cr} /(\mathrm{Cr}+\mathrm{Fe})$ remained in the range of 0-20 at. \%. All chemicals were purchased from Sigma Aldrich and used as received without any additional purification. Double deionized water, exhibiting a resistivity close to 15 $\mathrm{M} \Omega \cdot \mathrm{cm}$ was generated by a Milli-Q academic ultra-pure water purification system (Millipore, Bedford, MA, USA). Once the solution was prepared, some FTO glass substrates were placed at the bottom of a Teflon recipient. Only $20 \mathrm{ml}$ were transferred to the recipient so that the substrates were partially immersed in the solution. Then, the recipient was inserted in a stainless-steel autoclave. The filled autoclave was tightly sealed before being heated at $100{ }^{\circ} \mathrm{C}$ for $6 \mathrm{~h}$ in an oven. Finally, the system (autoclave with the samples) was naturally cooled down to room temperature.

Under hydrothermal conditions, the aqueous solution enables the $\mathrm{Fe}^{3+}$ hydrolysis ions with $\mathrm{OH}^{-}$ , producing iron oxide nuclei, as described by the following reaction (1):

$$
\mathrm{Fe}^{3+}(\mathrm{aq})+3 \mathrm{OH}_{(\mathrm{aq})}^{-} \rightarrow \mathrm{\beta}-\mathrm{FeOOH}_{(\mathrm{s})}+\mathrm{H}_{2} \mathrm{O}
$$

Finally, a uniform yellowish layer of akageneite $\beta$-FeOOH covered the FTO/glass substrates uniformly. The akageneite-coated substrates were then washed with deionized water and subsequently introduced in a muffle furnace to be sintered in air at $550{ }^{\circ} \mathrm{C}$ for 4 hours. At the end of this calcination step, the $\beta-\mathrm{FeOOH}$ was converted into $\alpha-\mathrm{Fe}_{2} \mathrm{O}_{3}$. Correspondingly, as illustrated in Figure 1, the color of the substrate turned from yellow to red-brown indicating a 
phase transition from $\beta-\mathrm{FeOOH}$ to $\boldsymbol{\alpha}-\mathrm{Fe}_{2} \mathrm{O}_{3}$ [57]. The chemical reaction expected to occur during this phase transition is represented by the reaction displayed below (2):

$$
2 \beta-\mathrm{FeOOH}_{(\mathrm{s})} \rightarrow \mathrm{Fe}_{2} \mathrm{O}_{3}(\mathrm{~s})+\mathrm{H}_{2} \mathrm{O}_{(\mathrm{L} \text { or G) }}
$$

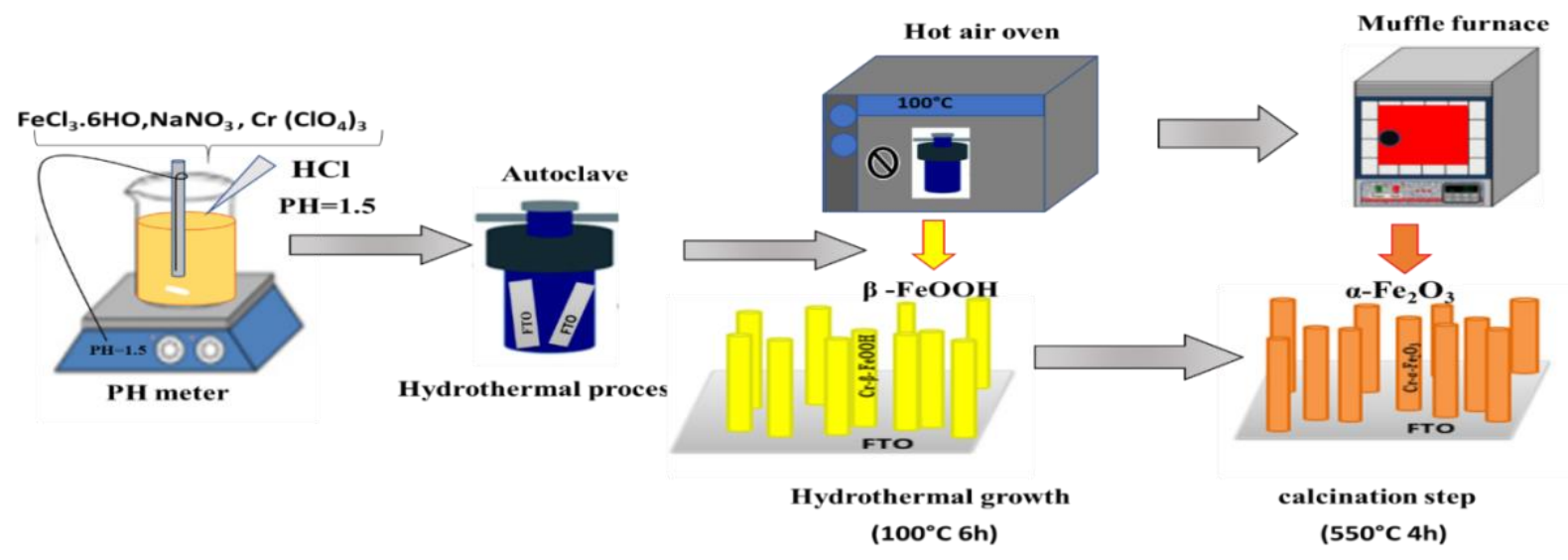

Fig.1. Schematic illustration of Cr-doped hematite photoanodes synthesized by the hydrothermal method.

\subsection{Characterization setup}

Microstructural properties of various hematite films were obtained at room temperature using a Rigaku Ultima IV X-ray diffractometer (XRD) in the Bragg-Bentano configuration using CuK $\alpha$ radiation $(\lambda=1.54060 \AA$ ). Chemical composition, surface morphology, and topography were characterized using energy dispersive spectroscopy (EDX) coupled to a field emission scanning electron microscope (FESEM) Zeiss ULTRA 55, equipped with an In-Lens SE detector. The selected electron diffraction and high-resolution transmission electron microscopy (HRTEM) images were obtained by a JEOL-2010 TEM set at an acceleration voltage of $200 \mathrm{kV}$. Optical absorption was recorded with a UV-visible spectrophotometer HR4000 provided by Ocean Optics. The spectrophotometer was coupled to an integrating sphere to collect both specular and diffuse transmittance.

The photoelectrochemical measurements of the samples were performed in a quartz cell to facilitate light reaching the photoelectrode surfaces. The surface area of the working electrode was $0.2 \mathrm{~cm}^{2}$. The electrolyte consisted of $1 \mathrm{M}$ solution of $\mathrm{NaOH}(\mathrm{pH}=13.6)$ with a pure nitrogen stream bubbling before and during the test to remove the dissolved oxygen. The chronoamperometric curves of the hematite thin films were also obtained at $+0.1 \mathrm{~V}$ (vs. $\mathrm{Ag} / \mathrm{AgCl}$ ) both in dark and under illumination performed by a $300 \mathrm{~W}$ Xenon lamp (PLSSXE300/300UV). The luminous intensity of the Xenon lamp was fixed at $100 \mathrm{mWcm}^{-2}$. 
The set-up was completed with an automatic shutter and a filter box. The whole system was controlled by homemade software.

For wavelength-dependent photocurrent measurements a monochromator giving a $\sim 20 \mathrm{~nm}$ bandpass from 360 to $680 \mathrm{~nm}$ was used together with cut off filters to eliminate secondary harmonics. To be able to detect low photocurrent intensity, the set-up was completed with a photo-chopper and a lock-in amplifier (signal recovery). The absolute intensity of the incident excitation light was measured with a radiometer/photometer (international light). The incident photon to electron conversion efficiency (IPCE) of the samples was calculated as follows:

$$
\operatorname{IPCE}(\%)=\frac{1240 \cdot i_{\text {photocurrent }}\left(\mu \mathrm{A} / \mathrm{cm}^{2}\right)}{\lambda(\mathrm{nm}) \cdot j_{\text {photons }}\left(\mu W / \mathrm{cm}^{2}\right)} * 100 \%
$$

Were $\mathrm{i}_{\text {photocurrent }}$ is the photocurrent densities, $\lambda(\mathrm{nm})$ is wavelength of the incident light and $\mathrm{j}_{\text {photons }}$ is the measured irradiance.

\section{Results and discussion}

\subsection{Morphological characterization}

\subsubsection{FESEM analysis}

The morphology of undoped and $\mathrm{Cr}$-doped $\boldsymbol{\alpha}-\mathrm{Fe}_{2} \mathrm{O}_{3}$ samples obtained under hydrothermal conditions was monitored by FESEM images (Figure 2). Figure 2 shows a typical morphology of hematite nanorod (NR) arrays grown on the FTO substrates by the hydrothermal process. Top view images show clearly that hematite NRs are uniformly distributed on the substrate and oriented upward with respect to the substrate. While others are detached from the substrate, being free standing and horizontal. Each hematite NR looks like a grain of rice as can be seen in Fig. 2 (a, b, c, d, and e (200 nm)) of the as-prepared sample, enabling the identification of a typical nanoparticle formation. On the other hand, top-view analysis of $\mathrm{Cr}$-doped $\boldsymbol{\alpha}$ - $\mathrm{Fe}_{2} \mathrm{O}_{3}$ electrodes synthesized during hydrothermal treatment $550{ }^{\circ} \mathrm{C}$ for $4 \mathrm{~h}$ showed that this substrate is formed by rods. The effect of different $\mathrm{Cr}$-doped $\boldsymbol{\alpha}-\mathrm{Fe}_{2} \mathrm{O}_{3}$ did not affect the morphology of the iron oxide nanoparticles. 


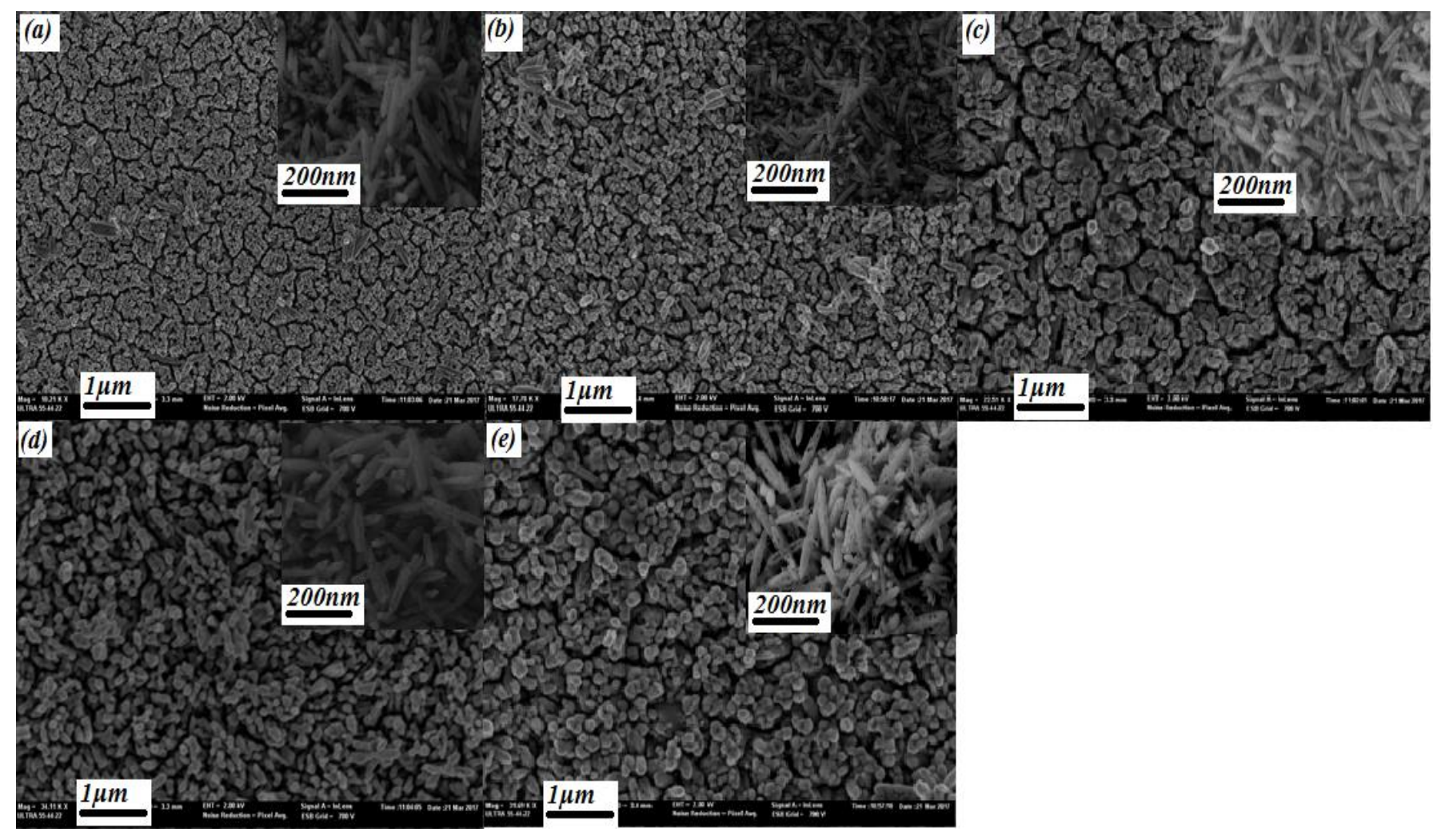

Fig.2. FESEM of hydrothermal deposited $\alpha-\mathrm{Fe}_{2} \mathrm{O}_{3}$ (a) undoped, (b) 4 at.\% $\mathrm{Cr}$, (c) 8 at. $\% \mathrm{Cr}$, (d) $16 \mathrm{at} . \% \mathrm{Cr}$, and (e) $20 \mathrm{at} . \% \mathrm{Cr}$ (1 $\mathrm{\mu m}$ and 200nm).

\subsubsection{HRTEM analysis}

The morphology of $\alpha-\mathrm{Fe}_{2} \mathrm{O}_{3}$ nanostructure films was characterized by TEM and HRTEM. Figure $3(a, b)$ shows a low magnification TEM image of the $\alpha-\mathrm{Fe}_{2} \mathrm{O}_{3}$ nanostructures analyzed shows that the as-synthesized NRs exhibit a smooth surface and a relatively uniform diameter along the axial direction, using the high-resolution transmission electron microscopy (HRTEM) technique Figure 3 (c, d, e, f) shows a clear interplanar distance of $2.24 \mathrm{~nm}$, matching the $\mathrm{d}_{110}$ spacing of pure hexagonal hematite. The NRs tend to have a parallel alignment, owing to weak Van der Waals attraction. The inset displays the electron diffraction (ED) pattern, which was taken of the entire area. The diffraction ring indicates the polycrystalline nature of $\alpha-\mathrm{Fe}_{2} \mathrm{O}_{3}$ and is highly consistent with the XRD results (Figure 4). Furthermore, the elemental mapping images (Figure $3 \mathrm{~B}$ ) of the $\mathrm{Fe}(\mathrm{K} \alpha), \mathrm{O}(\mathrm{K} \alpha), \mathrm{Cr}(\mathrm{K} \alpha)$ nanorod reveal that the Cr dopants are distributed over all the nanostructures without any segregation on the surface or inside the crystals. 


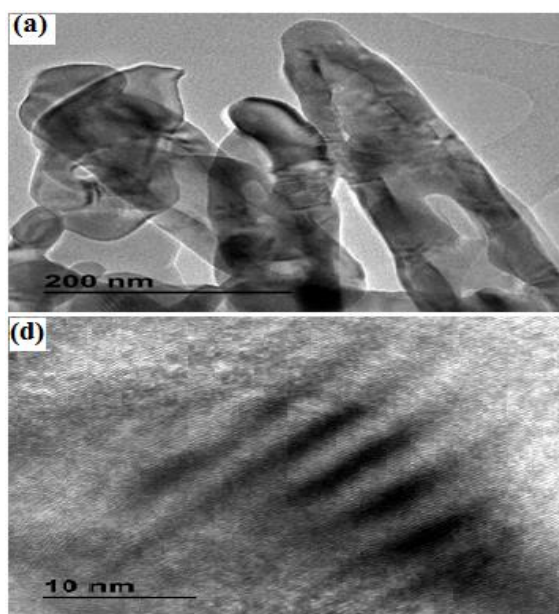

Fe K $\alpha 1$

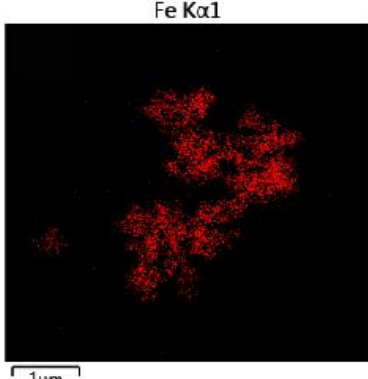

$1 \mu \mathrm{m}$

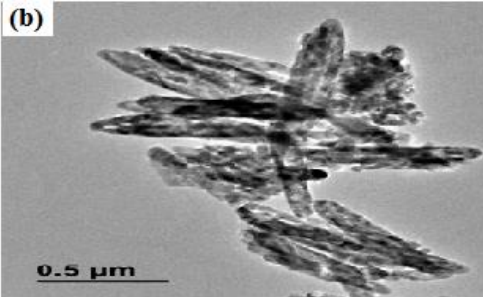

$(\mathbf{e}) \cdot$

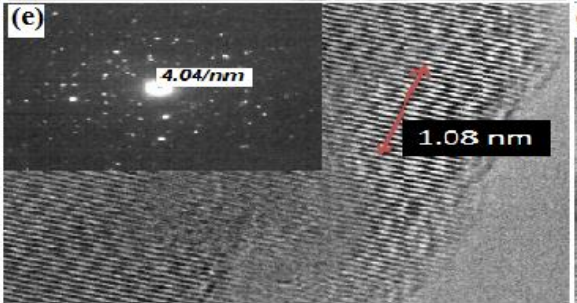

$\mathrm{O} K \alpha \mathrm{l}$

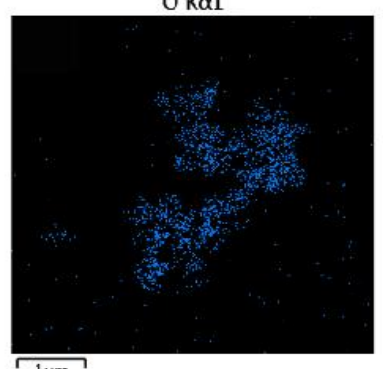

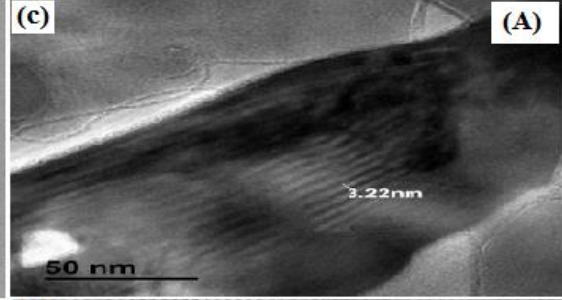

(f)

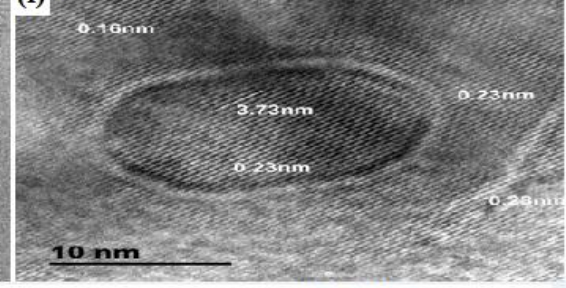

$\mathrm{Cr}-\mathrm{Fe}_{2} \mathrm{O}_{3}$
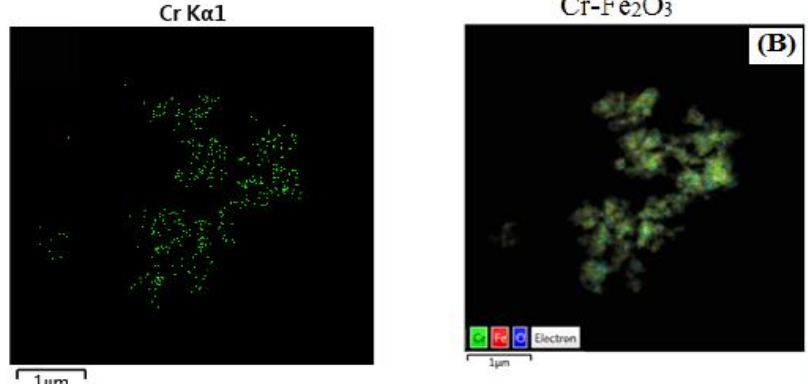

(B)

Fig.3 :(A) HRTEM of hydrothermally deposited undoped $\alpha-\mathrm{Fe}_{2} \mathrm{O}_{3}$, (B) Element Mapping images of the $\mathrm{Cr}-\mathrm{Fe}_{2} \mathrm{O}_{3}$ photoanode.

\subsection{Structural characterization}

Figure 4 shows the XRD patterns of doped and undoped hematite films. The diffraction peaks match the JCPDS Card No. 33-0664.Diffraction peaks located at $2 \theta=24.2^{\circ}, 33.1^{\circ}, 35.6^{\circ}$, $40.9^{\circ}, 49.5^{\circ}, 54.1^{\circ}$ and $64^{\circ}$ correspond to (012), (104), (110), (113), (024), (116) and (300) diffraction planes, respectively. No peak corresponding to mixed oxides or impurities was detected in any of the samples. Hematite $\left(\boldsymbol{\alpha}-\mathrm{Fe}_{2} \mathrm{O}_{3}\right)$ belongs to the space group R-3c (167) with the lattice parameters $a=5.036 \AA, b=5.036 \AA$, and $c=13.74 \AA$. This result proves that after being heated in air at $550^{\circ} \mathrm{C}$ for $4 \mathrm{~h}$, the precursor was completely converted from $\mathrm{FeOOH}$ to a pure $\alpha-\mathrm{Fe}_{2} \mathrm{O}_{3}$ rhombohedral phase. Hence, undoped and $\mathrm{Cr}$-doped hematite films have the same crystal structure as $\boldsymbol{\alpha}-\mathrm{Fe}_{2} \mathrm{O}_{3}$.

The crystallite size of the samples was calculated using the Debye-Scherer formula:

$$
\boldsymbol{D}=\frac{(\mathrm{K} \lambda)}{(\boldsymbol{\beta} \cos \theta)}
$$

where $\lambda=1.5405 \AA$ is the wavelength of $\mathrm{Cu} \mathrm{K} \alpha$ radiation, $\beta$, the full width at half maximum (FWHM) of the main diffraction peak in radian, $\theta$, the Bragg angle and $\mathrm{k}$, the Scherrer's constant equal to 0.90 . 
Table 1 displays the calculated crystallite sizes for hematite samples doped at different $\mathrm{Cr}$ concentrations for the most intense peaks that correspond to (012) and (110) diffraction planes. The average crystallite size was found to decrease from $44 \mathrm{~nm}$ to $11.7 \mathrm{~nm}$ for (012) and 40.6 $\mathrm{nm}$ to $4.8 \mathrm{~nm}$ for (110) as Cr doping varied from $0 \%$ to $20 \%$, leading to a gradual decline of the intensity of the (012) and (110) XRD lines (See Fig. 4). The shift to higher angles observed for XRD peaks as $\mathrm{Cr}$ content increases (Table 1) confirms the replacement of $\mathrm{Fe}^{2+}$ ions (ion radius $=0.74 \AA$ ) by the smaller $\mathrm{Cr}^{3+}$ ions (ion radius $=0.69 \AA$ ). This replacement results in a contraction of the $\boldsymbol{\alpha}-\mathrm{Fe}_{2} \mathrm{O}_{3}$ lattice. It is also worth noting that EDX and optical analysis confirmed Cr-doping.

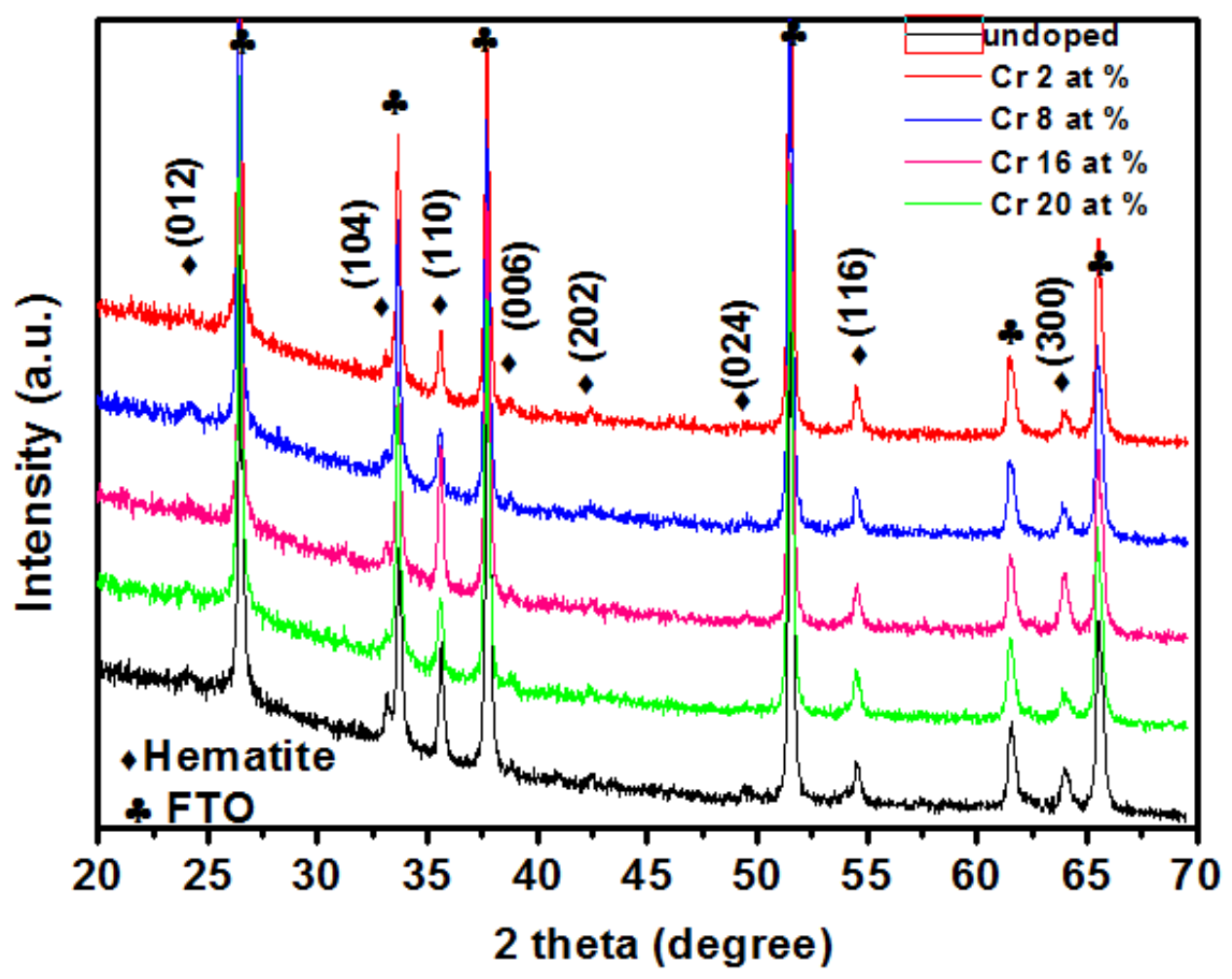

Fig.4. XRD patterns of $\alpha-\mathrm{Fe}_{2} \mathrm{O}_{3}$ and $\mathrm{Cr}$-doped $\alpha-\mathrm{Fe}_{2} \mathrm{O}_{3}$ films at different $\mathrm{Cr}$ concentrations.

Table1: Variation of the crystallite size of undoped and $\mathrm{Cr}$-doped $\alpha-\mathrm{Fe}_{2} \mathrm{O}_{3}$ vs $\mathrm{Cr}$ content.

\begin{tabular}{|c|c|c|c|c|}
\hline Sample ID & $\begin{array}{c}2 \theta\left(^{\circ}\right) \\
\text { Peak }(012)\end{array}$ & $\begin{array}{c}\text { Crystallite } \\
\text { Size [nm] }\end{array}$ & $\begin{array}{c}2 \theta\left(^{\circ}\right) \\
\text { Peak }(110)\end{array}$ & $\begin{array}{c}\text { Crystallite } \\
\text { Size [nm] }\end{array}$ \\
\hline $\mathrm{Fe}_{2} \mathrm{O}_{3}$ & 24.13 & 44.0 & 33.14 & 40.6 \\
\hline $\mathrm{Fe}_{2} \mathrm{O}_{3}: \mathrm{Cr} 4 \%$ & 24.21 & 31.6 & 33.24 & 31.5 \\
\hline $\mathrm{Fe}_{2} \mathrm{O}_{3}: \mathrm{Cr} 8 \%$ & 24.28 & 23.2 & 33.26 & 23.1 \\
\hline $\mathrm{Fe}_{2} \mathrm{O}_{3}: \mathrm{Cr} 16 \%$ & 24.30 & 17.7 & 33.28 & 18.6 \\
\hline $\mathrm{Fe}_{2} \mathrm{O}_{3}: \mathrm{Cr} 20 \%$ & 24.32 & 11.7 & 33.33 & 4.8 \\
\hline
\end{tabular}




\subsection{EDX analysis}

Elemental analysis of the $\boldsymbol{\alpha}-\mathrm{Fe}_{2} \mathrm{O}_{3}$ thin films was done by Energy Dispersive X-ray analysis (EDX) spectra (Fig. 5). The L line of the Fe element peaks at $0.6398 \mathrm{keV}$, while the K-line of oxygen peaks at $0.525 \mathrm{keV}$. The atomic percentages of $\mathrm{Fe}, \mathrm{Cr}$, and $\mathrm{O}$ in undoped and $\mathrm{Cr}$-doped $\boldsymbol{\alpha}-\mathrm{Fe}_{2} \mathrm{O}_{3}$ are shown in Fig. 5. The excess of oxygen (detected by EDX) could have arisen from $\mathrm{SnO}_{2}$, as all Cr-doped films keep the hematite structure, it can be assumed that the films do not deviate excessively from the stoichiometric composition. The calculated atomic ratio of Fe and $\mathrm{O}$ is approximately equal to $2: 3$, which agrees with the stoichiometric composition of $\alpha-\mathrm{Fe}_{2} \mathrm{O}_{3}$, indicating that the films are rather thick so that only oxygen coming from the hematite is detected. On the other hand, the $\mathrm{Cr}$ concentration in the films is different from that existing in the precursor solution.

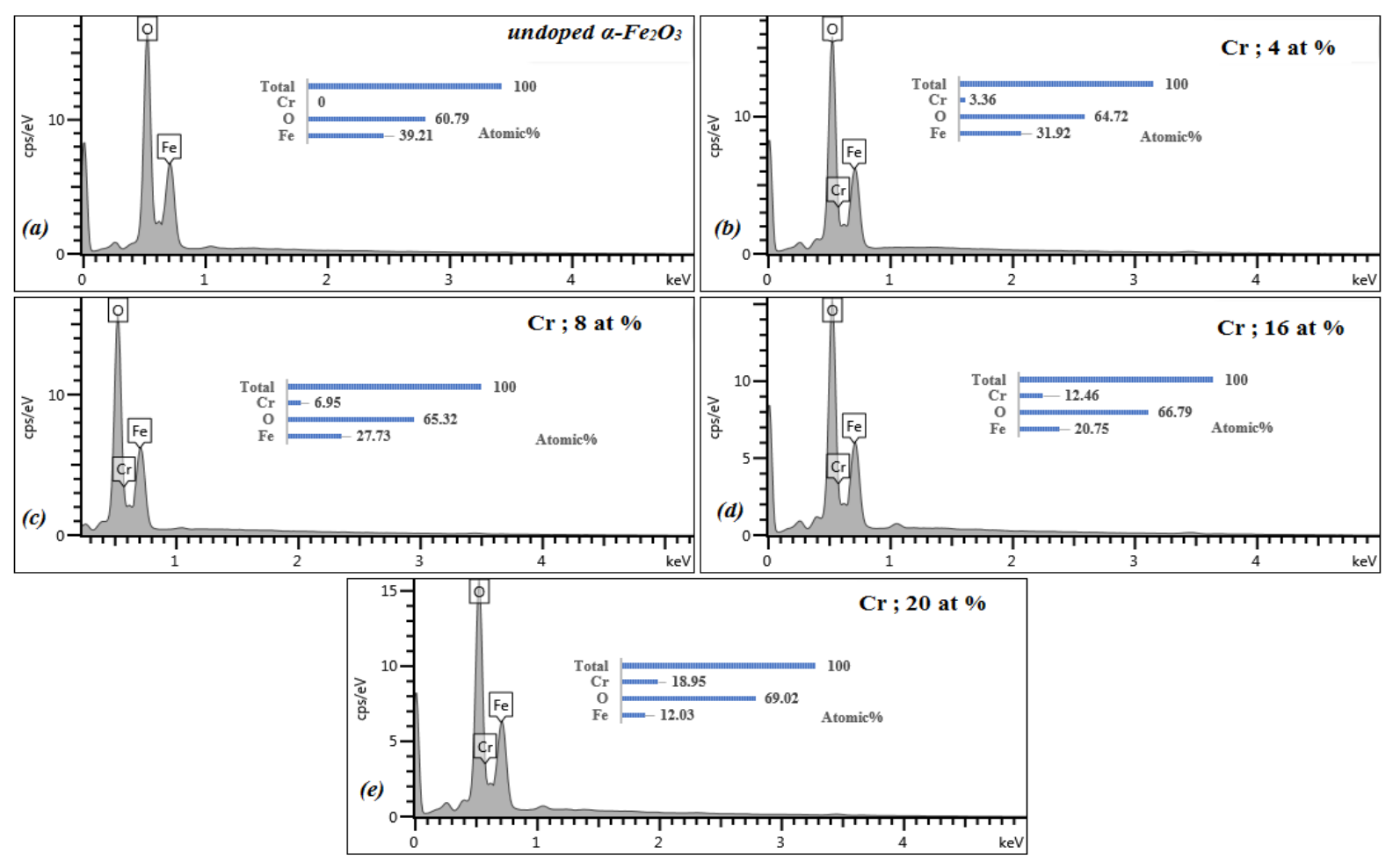

Fig.5. EDX spectrum of (a) undoped $\alpha-\mathrm{Fe}_{2} \mathrm{O}_{3},(b) 4$ at.\% $\mathrm{Cr}$-doped $\alpha-\mathrm{Fe}_{2} \mathrm{O}_{3}$, (c) 8 at. \% Crdoped $\alpha-\mathrm{Fe}_{2} \mathrm{O}_{3}\left(\right.$ (d) 16 at. \% Cr-doped $\alpha-\mathrm{Fe}_{2} \mathrm{O}_{3}$ and (e) 20 at.\% Cr-doped $\alpha-\mathrm{Fe}_{2} \mathrm{O}_{3}$.

\subsection{Optical characterization of $\mathrm{Cr}$-doped $\mathrm{Fe}_{2} \mathrm{O}_{3}$ thin films}

Figure 6 shows the optical transmission spectra in the wavelength range of 450 to $800 \mathrm{~nm}$. The films displayed a transparency above $65 \%$ with an excitation wavelength above $600 \mathrm{~nm}$. With increasing Cr content, the absorption edge (550-700 nm) shifted towards the longer wavelength 
region. It appears that $\boldsymbol{\alpha}-\mathrm{Fe}_{2} \mathrm{O}_{3}$ has a high absorbance in the blue region, indicating its applicability as an absorbing material in this wavelength range (Figure 7).

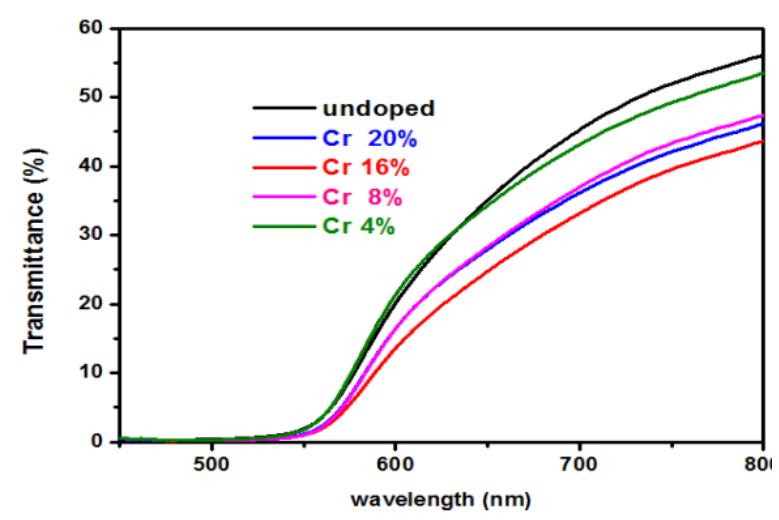

Fig.6. Transmittance spectra of undoped and $\mathrm{Cr}$ doped $\alpha-\mathrm{Fe}_{2} \mathrm{O}_{3}$

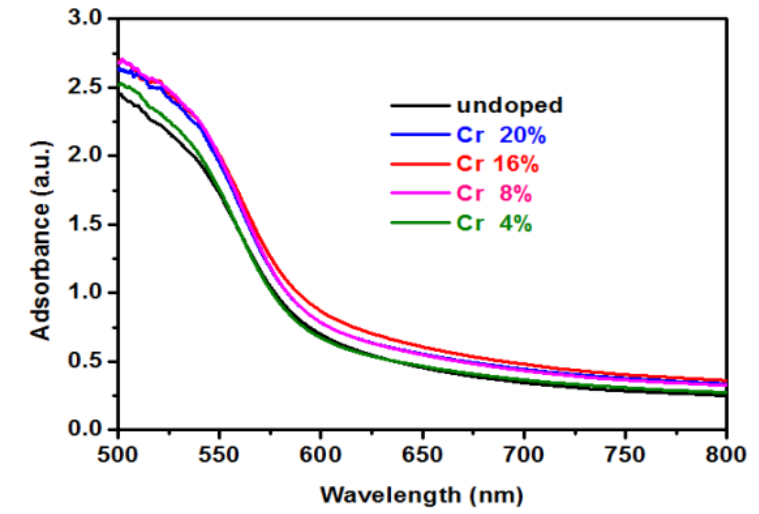

Fig.7. Absorbance spectra of undoped and $\mathrm{Cr}$ doped $\alpha-\mathrm{Fe}_{2} \mathrm{O}_{3}$

The effect of Cr-doping on the band-gap energy of the synthesized films was determined from the Tauc plot. The band-gap energy $\left(E_{g}\right)$ is estimated from the optical transmission spectra by calculating the absorption coefficient as follows [30]:

$$
\alpha=\frac{1}{\mathrm{~d}} \ln \left(\frac{1}{\mathrm{~T}}\right)
$$

The relation between the absorption coefficient and the incident light energy hv is approximated as [62]:

$$
\alpha h v=A(h v-E g)^{n}
$$

where $\boldsymbol{\alpha}$ is the absorption coefficient, $\boldsymbol{A}$ is a constant, $\boldsymbol{h}$ is the Planck's constant, $\boldsymbol{v}$ is the photon frequency, $E_{g}$ is the optical bandgap, and $n$ is equal to $1 / 2$ for direct bandgap transitions and 2 for indirect ones. Figure 8 shows the Tauc plot for direct bandgap transitions for undoped and $\mathrm{Cr}$-doped $\boldsymbol{\alpha}-\mathrm{Fe}_{2} \mathrm{O}_{3}$ films. The optical band-gap energy of undoped $\boldsymbol{\alpha}-\mathrm{Fe}_{2} \mathrm{O}_{3}$ films was estimated to be $2.154 \mathrm{eV}$, slightly lower than that of bulk $\boldsymbol{\alpha}-\mathrm{Fe}_{2} \mathrm{O}_{3}(2.3 \mathrm{eV})$. It can be observed that the optical band-gap of $\mathrm{Cr}$-doped $\boldsymbol{\alpha}-\mathrm{Fe}_{2} \mathrm{O}_{3}$ remains in the range of $2.05 \mathrm{eV}-2.1 \mathrm{eV}$ (Table 2). 


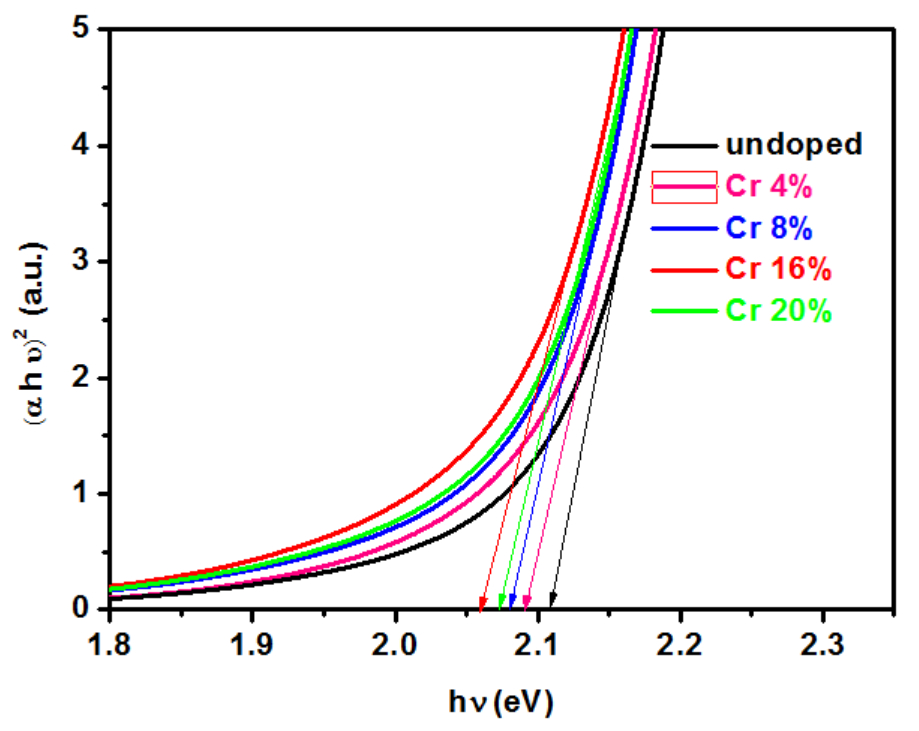

Fig.8. Tauc plot of undoped and $\mathrm{Cr}$-doped $\alpha-\mathrm{Fe}_{2} \mathrm{O}_{3}$

Table 2. Optical band-gap for $\alpha-\mathrm{Fe}_{2} \mathrm{O}_{3}$ thin films having different $\mathrm{Cr}$-doping

\begin{tabular}{|c|c|c|c|c|c|}
\hline$\alpha-\mathrm{Fe}_{2} \mathrm{O}_{3}$ : Cr-doping & $\mathrm{Cr} 0 \%$ & $\mathrm{Cr} 4 \%$ & $\mathrm{Cr} 8 \%$ & $\mathrm{Cr} 16 \%$ & $\mathrm{Cr} 20 \%$ \\
\hline $\begin{array}{c}\text { Bandgap energy (Eg) } \\
(\mathrm{eV})\end{array}$ & 2.15 & 2.09 & 2.08 & 2.05 & 2.07 \\
\hline
\end{tabular}

\subsection{Photoelectrochemical properties of the $\mathrm{Cr}$-doped $\alpha$-Fe $\mathrm{F}_{2} \mathrm{O}_{3}$ electrode.}

The photocurrent response was measured under visible light irradiation. To improve the photocurrent response of $\boldsymbol{\alpha}-\mathrm{Fe}_{2} \mathrm{O}_{3}$ films the charge carrier transport must be enhanced in bulk and on the surface to reduce carrier recombination at both sites. All measurements were made in $1 \mathrm{M} \mathrm{NaOH}[63,64]$ electrolyte and under a potential bias of $0.4 \mathrm{~V}$.

Furthermore, we conducted chronoamperometric measurements under repeated light-on and light-off conditions for all hematite films with and without $\mathrm{Cr}$ doping. As shown in Fig. 9, the photocurrent of hematite is low and all Cr-doped hematite films exhibit higher photocurrents than undoped ones. Hematite films with 16 at. \% of Cr displays the highest photocurrent, which is consistent with the UV-vis.

The results clearly demonstrate that the photocurrent density generated from the $\mathrm{Cr}$-doped $\alpha$ $\mathrm{Fe}_{2} \mathrm{O}_{3}$ electrode is significantly higher than that of undoped electrodes due to the presence of an easier electron transport mechanism. In fact, structural studies showed that XRD peaks exhibited a slight shift towards higher diffraction angles as $\mathrm{Cr}$ doping increases, which indicates that $\mathrm{Fe}^{3+}$ ions were replaced by smaller $\mathrm{Cr}^{4+}$ ions. Accordingly, $\mathrm{Cr}\left(\mathrm{Cr}^{4+}\right)$ acts as an electron donor in the $\boldsymbol{\alpha}-\mathrm{Fe}_{2} \mathrm{O}_{3}$ matrix, thus confirming the substitution of $\mathrm{Fe}^{3+}$ by $\mathrm{Cr}^{4+}$ ions. 
In fact, $\mathrm{Cr}$ doping increases the donor concentration and enhances the charge carrier transportation by increasing the electric field across the space charge layer. The growth of the donor concentration would reduce the width of the space charge layer; hence, the charge carriers within the region should be efficiently separated before recombination. On the other hand, a higher concentration of dopant would provide more efficient defect-scattering/recombination inhibiting the increased separation efficiency, which might also explain the variation of the photocurrent density with the doping levels.

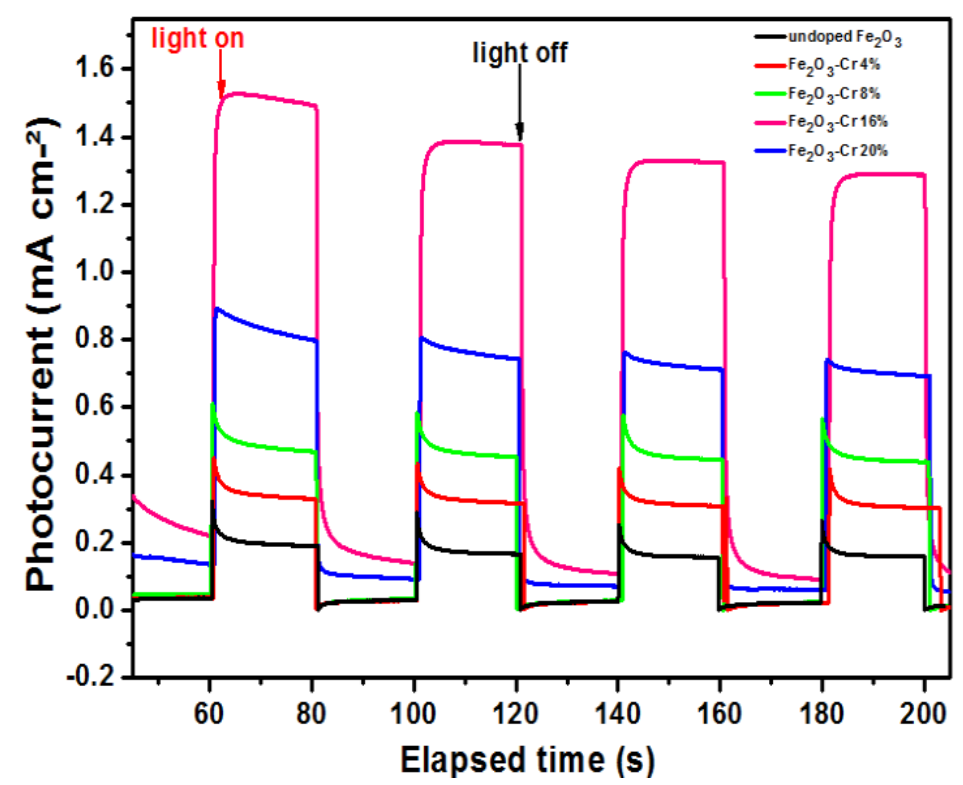

Figure 9: Photocurrent intensity for $\mathrm{Cr}$-doped $\mathrm{Fe}_{2} \mathrm{O}_{3}$ electrodes under on/off illumination, measured in $1 \mathrm{M} \mathrm{NaOH}$ electrolyte with a bias potential of $+0.4 \mathrm{~V}$, under successive illumination cycles.

Figure 10 shows the performance of doped samples as compared to undoped sample. Significant performance enhancements were observed upon doping throughout the illumination wavelengths. The performance of the 4 at.\% Cr-doped films is 4 times higher than that of the undoped sample. The IPCE of 16 at.\% Cr-doped films measured at $400 \mathrm{~nm}$ with an applied bias of $+0.4 \mathrm{~V}$ (vs. $\mathrm{Ag} / \mathrm{AgCl}$ ) is $6 \%$, which corresponds to a thirty-fold improvement over the undoped hematite. The higher photon energy was absorbed in the outmost layers of hematite and therefore, the photogenerated holes have a shorter diffusion path to reach the surface where they will contribute in $\mathrm{H}_{2} \mathrm{O}$ oxidation reaction. An anodic applied bias will increase the collection efficiency of the electrons, and an IPCE improvement can be seen in Figure 10. Furthermore, the applied bias will enable $\mathrm{H}_{2} \mathrm{O}$ reduction at the $\mathrm{Pt}$ counter-electrode by overcoming the mismatch $(0.4 \mathrm{~V}$ (vs. $\mathrm{Ag} / \mathrm{AgCl}))$ between the hematite conduction band edge level and the reversible hydrogen potential (see Figure 11). The improved IPCE performance is implausible to be related to an increase in the absorption of the doped samples since no 
significant change was obtained in the absorption spectra of the different $\mathrm{Cr}$-doped samples (see Figure 7).

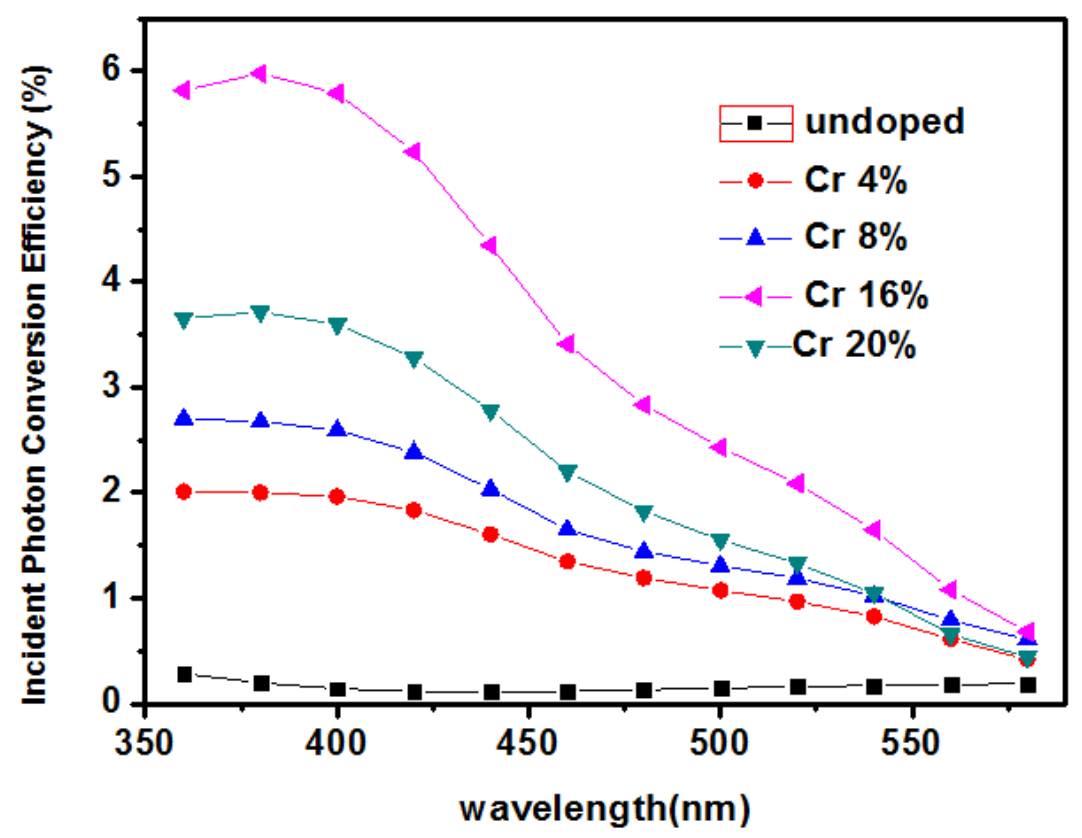

Fig.10. IPCE for undoped and $\mathrm{Cr}$-doped $\alpha-\mathrm{Fe}_{2} \mathrm{O}_{3}$ films at an applied potential of $+0.4 \mathrm{~V}$ (vs. $\mathrm{Ag} / \mathrm{AgCl}$ ) inl $\mathrm{M} \mathrm{NaOH}$.

(HER) : Counter Cathode $4 \mathrm{H}_{2} \mathrm{O}+4 \mathrm{e}^{-} \rightarrow \mathbf{4 O \mathrm { H } ^ { - }}+\mathbf{2} \mathrm{H}_{2}$

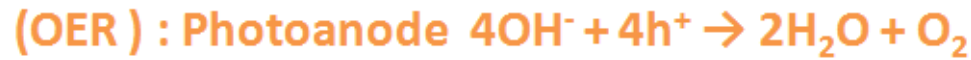
2hv $+\mathrm{H}_{2} \mathrm{O} \rightarrow \mathrm{H}_{2}+1 / 2 \mathrm{O}_{2}$ Net PEC water-splitting

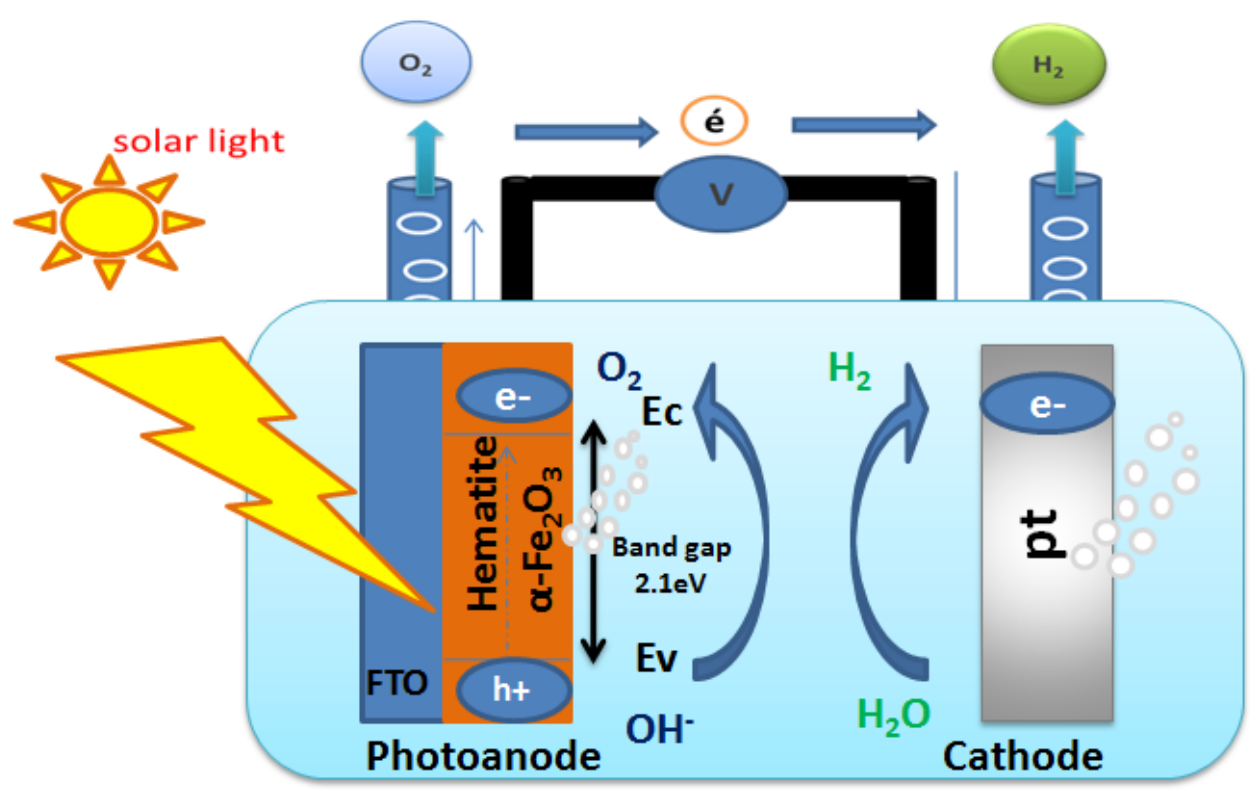

Fig.11. Energy diagram of the n-type hematite photoanode and schematic illustration of the photoelectrochemical water splitting on photoanode and cathode. 


\section{Conclusions}

$\mathrm{Cr}$-doped $\boldsymbol{\alpha}-\mathrm{Fe}_{2} \mathrm{O}_{3}$ films were successfully deposited on FTO-coated glass substrates using the hydrothermal method and an annealing process. The concentration of the incorporated $\mathrm{Cr}$ atoms $\left(\mathrm{Cr}^{4+}\right.$ ions) was controlled by varying the concentration of the $\mathrm{Cr}\left(\mathrm{ClO}_{4}\right)_{3}$ precursor solution, (i.e., the concentration of the dopant in the sample can be controlled by adjusting the electrolyte composition). The $\mathrm{Cr}$ dopant served as an ionized donor and was found to increase the carrier density of the $\boldsymbol{\alpha}-\mathrm{Fe}_{2} \mathrm{O}_{3}$ films. The major effect of $\mathrm{Cr}$ atoms is the improvement of the conductivity and the charge transport properties of the $\boldsymbol{\alpha}-\mathrm{Fe}_{2} \mathrm{O}_{3}$ films. The photoactivity of the iron oxide was improved by co-deposition with $\mathrm{Cr}$. The best performing samples have a doping rate of 16 at $\% \mathrm{Cr}$, which in turn has an IPCE of $6 \%$ at $400 \mathrm{~nm}$, with an applied potential of $+0.4 \mathrm{~V}$ (vs $\mathrm{Ag} / \mathrm{AgCl}$ ). These IPCE values were thirty times higher than that of the undoped sample. Hence, a greater fraction of the photon-generating electron-hole pairs is available for surface redox chemistry. The apparent optimum at 16 at.\% $\mathrm{Cr}$ doping may balance these competing effects most effectively and yield the best PCE performance. The $\mathrm{Cr}$-doped $\boldsymbol{\alpha}-\mathrm{Fe}_{2} \mathrm{O}_{3}$ films provide potential applications in photocatalysis for water splitting or in photoelectrical devices.

\section{Acknowledgements}

This work was supported by the Ministry of High Education and Scientific Research, Tunisia and Ministerio de Economía y Competitividad (ENE2016-77798-C4-2-R) and Generalitat Valenciana (Prometeus 2014/044).

\section{References}

[1] A. B.Murphy, P. R. F.Barnes, L. K. Randeniya, I. C. Plumb, Grey, M. D. Horne, \& J. A Glasscock, International Journal of Hydrogen Energy, 31(14) (2006), 1999-2017.

[2] Z.B. Chen, T. F. Jaramillo, T. G. Deutsch, A. Kleiman-Shwarsctein, A. J. Forman, N. Gaillard, R. Garland, K. Takanabe, C. Heske, M. Sunkara, E. W. McFarland, K. Domen, E. L. Miller, J. A. Turner and H. N. Dinh, J. Mater. Res., (2010), 25, 3.

[3] K. Sivula, F. L. Formal, M. Grätzel, ChemSusChem, 4, (2011), 432-449.

[4] T.W. Hamann, Dalton Trans., 41, (2012) 7830-7834.

[5] V. M. Aroutiounian, V. M. Arakelyan, G. E. Shahnazaryan, H. R. Hovhannisyan, H. L. Wang, J. A. Turner, Sol. Energy 2007, 81, 1369.

[6] J. S. Jang, J. Lee, H. Ye, F. R. F. Fan, A. J. Bard, J. Phys. Chem. C 2009, 113, 6719 
[7] Y. S. Hu, A. Kleiman-Shwarsctein, A. J. Forman, D. Hazen, J. N.Park, E. W. McFarland, Chem. Mater. 2008, 20, 3803.

[8] I. Cesar, A. Kay, J. A. G. Martinez, M. Gratzel, J. Am. Chem. Soc. 2006, 128, 4582.

[9] S. Saremi-Yarahmadi, K. G. U. Wijayantha, A. A. Tahir, B. Vaidhyanathan, J. Phys. Chem. C 2009, 113, 4768.

[10] Y.Q. Liang, C.S. Enache, R. van de Krol, Int. J. Photoenergy 2008 (2008) 1.

[11] I. Cesar, K. Sivula, A. Kay, R. Zboril, M. Gratzel, J. Phys. Chem. C 113 (2009) 772.

[12] Y. S. Hu, A. Kleiman-Shwarsctein, G. D. Stucky, E. W. McFarland, Chem. Commun. 2009, 2652.

[13] F. Morin, J. Phys. Rev. 1951, 83, 1005.

[14] J.S. Jang, J. Lee, H. Ye, F.R.F. Fan, A.J. Bard, J. Phys. Chem. C 113 (2009) 6719.

[15] A. Kleiman-Shwarsctein, M. N. Huda, A. Walsh, Y. F. Yan, G. D. Stucky, Y. S. Hu, M. M. Al Jassim, E. W. McFarland, hem. Mater. 2010, 22, 510.

[16] A. Bak, W. Choi, H. Park, Appl. Catal. B 2011, 110, 207.

[17] A. Kleiman-Shwarsctein, Y. S. Hu, A. J. Forman, G. D. Stucky, E. W. McFarland, J. Phys. Chem. C 2008, 112, 15900.

[18] V. M. Aroutiounian, V. M. Arakelyan, G. E. Shahnazaryan, G. M. Stepanyan, E. A. Khachaturyan, H. Wang, J. A. Turner,Sol. Energy 2006, 80, 1098.

[19] K. Gurunathan, P. Maruthamuthu, Int. J. Hydrogen Energy 20 (1995) 287.

[20] G.K. Reddy, K. Gunasekara, P. Boolchand, P.G. Smirniotis, J. Phys. Chem. C 115 (2011) 920 .

[21] R. Schrebler, L. Ballesteros, A. Burgos, E.A. Dalchiele, J. Electrochem. Soc. 158 (2011) D500.

[22] C.L. Chun, D.R. Baer, D.W. Matson, J.E. Amonette, R.L. Penn, Environ. Sci Technol. 44 (2010) 5079.

[23] J. Velev, A. Bandyopadhyay, W. H. Butler, S. Sarker, Phys.Rev. B 2005, 71, 205208.

[24] A.A. Akl, Appl.Surf.Sci.233(2004)307.

[25] C.D. Park, J. Walker, R. Tannenbaum, A.E. Stiegman, J. Frydrych, L. Machala, ACS Appl.Mater.Int.1(2009)1843.

[26] A. Watanabe, H. Kozuka, J. Phys. Chem. B 107 (2003) 12713.

[27] A. Memar, W. R. W. Daud, S. Hosseini, E. Eftekhari, L. J. Minggu, Sol. Energy 2010, 84, 1538. 
[28] C.J. Jia, L.D. Sun, Z.G. Yan, L.P. You, F. Luo, X.D. Han, Y.C. Pang, Z. Zhang, C.H. Yan, Angew. Chem. Int.Ed.44(2005)4328.

[29] K. Sue, T. Sato, S. Kawasaki, Y. Takebayashi, S. Yoda, T. Furuya, T. Hiaki, Ind. Eng. Chem. Res. 49 (2010) 8841.

[30] E.L. Miller, D.Paluselli, B.Marsen, R.E. Rocheleau, Thin Solid Films 466 (2004) 307.

[31] Z.H. Zhang, M.F. Hossain, T. Miyazaki, T. Takahashi, Environ. Sci. Technol. 44 (2010)4741.

[32] M. Aronniemi, J. Saino, J. Lahtinen, ThinSolidFilms516(2008)6110.

[33] W. Widiyastuti, R. Balgis, F. Iskandar, K. Okuyama, Chem. Eng. Sci. 65 (2010) 1846.

[34] A. Duret, M. Gratzel, J. Phys. Chem. B 2005, 109, 17184.

[35] C. J. Sartoretti, B. D.Alexander, R. Solarska, W. A. Rutkowska, J. Augustynski, R. Cerny, J. Phys. Chem. B 2005, 109,13685.

[36] S. Saremi-Yarahmadi, K. G. U. Wijayantha, A. A. Tahir,B.Vaidhyanathan, J. Phys. Chem. C 2009, 113, 4768.

[37] A. Kay, I. Cesar, M. Gratzel, J. Am. Chem. Soc. 2006,128, 15714.

[38] Y.S. Hu, A. Kleiman-Shwarsctein, A.J. Forman, D. Hazen, J.N. Park, E.W. McFar-land, Chem.Mater.20 (2008) 3803.

[39] A. Kleiman-Shwarsctein, M.N. Huda, A. Walsh, Y.F. Yan, G.D. Stucky, Y.S. Hu,M.M. Al-Jassim, E.W. McFarland, Chem.Mater.22(2010)510.

[40] R. L. Spray, K. S. Choi, Chem. Mater. 2009, 21, 3701.

[41] A. Bak, W. Choi, H. Park, Appl. Catal. B 2011, 110, 207.

[42] U. Bjorksten, J.Moser, M. Gratzel,Chem Mater 1994, 6, (6), 858-863.

[43] H. L. Wang, J.A. Turner, J.Electrochem. Soc. 2010, 157, (11), F173-F178.

[44] L. Vayssieres, J.H. Guo, J. Nordgren, J. Nanosci.Nanotechno.2001, 1, (4),385-388.

[45] L. Li, Y. Yu, F. Meng, Y. Tan, R.J. Hamers, S. Jin, Nano Lett. 2012, 12, (2), 724-731.

[46] M. Grätzel, Photoelectrochemical cells, NATURE VOL 41415 NOVEMBER 2001

[47] A. Boudjemaa, S. Boumaza, M. Trari, R. Bouarab, A. Bougueliac, Physical and photoelectrochemical characterizations of a-Fe ${ }_{2} \mathrm{O}_{3}$.Application for hydrogen production, International Journal of Hydrogen Energy 34 (2009) 4268-4274

[48] A. Boudjemaa, M. Trari, Photo-catalytic hydrogen production over $\mathrm{Fe}_{2} \mathrm{O}_{3}$ based catalysts international journal of hydrogen energy 35 (2010) 7684 -7689.

[49] J. H. Kennedy and K. W. Frese, Jr, J. Electrochem. Soc., 1978, 125(5), 709-714 
[50] M.P. Dare-Edwards, J.B. Goodenough, A.Hamnett, P.R. Travelling, J. Chem. Soc. Faraday Trans. I 1983,79, 2027-2041

[51] A. Mao, G.Y. Han, J.H. Park, Journal of Materials Chemistry 20 (2010) 2247-2250.

[52] C. J. Sartoretti, B.D. Alexander, R. Solarska, W.A.Rutkowska, J.Augustynski, R. Cerny, J Phys Chem B 2005, 109, (28), 13685-13692.

[53] J.A. Glasscock, P. R. F. Barnes, I.C. Plumb, N.Savvides, Journal ofPhysical Chemistry C 2007, 111, (44), 16477-16488.

[54] Yichuan Ling, Gongming Wang, Damon A. Wheeler, Jin Z. Zhang, and Yat Li, Nano Lett., 2011, 11 (5), 2119-2125

[55] Yanming Fu, Chung-Li Dong, Zhaohui Zhou, Wan-Yi Lee, Jie Chen, Penghui Guo, Liang Zhao and ShaohuaShen Phys. Chem. Chem. Phys., 2016,18, 3846-3853

[56] S. Kumari, A.P. Singh, Sonal, D. Deva, R. Shrivastav, S. Dass, V.R. Satsangi, Int. J. Hydrogen Energy 2010, 35, 3985-3990.

[57] W.B. Ingler Jr, S.U.M. Khan; Thin Solid Films 2004, 461, 301-308.

[58] W.B. Ingler, Jr., J.P.Baltrus, S.U.M. Khan; J. Am. Chem. Soc. 2004, 126, 10238-10239.

[59] L. Vayssieres, N. Beermann, S.E. Lindquist, A. Hagfeldt, Controlled aqueous chemical growth of oriented three-dimensional crystalline nanorod arrays: application to iron(III) oxides, Chem. Mater. 13 (2001) 233-235.

[60] A. Annamalai, P.S. Shinde, A. Subramanian, J.Y. Kim, J.H. Kim, S.H. Choi, J.S. Lee, J.S. Jang, J. Mater. Chem. A 3 (2015) 5007-5013.

[61] Mingyang Li, Ziyang Zhang, Feiyi Lyu, Xinjun He, Zhihao Liang, Muhammad-Sadeeq Balogun, Xihong Lu, Ping-Ping Fang, Yexiang Tong, Electrochim. Acta, 186 (2015) 95-100.

[62] M.R. Belkhedkar, A.U. Ubale, International Journal of Materials and Chemistry, 4 (2014) 109-116.

[63] S.S. Shinde, R. A. Bansode, C. H. Bhosale, and K.Y. Rajpure, Journal of Semiconductors 32 (2011) 013001.

[64] Flavio L. Souza, Kirian P. Lopes, Pedro A.P. Nascente, Edson R. Leite, Solar Energy Materials \& Solar Cells 93(2009) 362-368. 